\title{
Stribeck Friction Curve in Point EHL Contacts
}

\author{
Hiroshi Nishikawa* and Motohiro Kaneta \\ Department of Mechanical and Control Engineering, Faculty of Engineering, \\ Kyushu Institute of Technology, 1-1 Sensui-cho, Tobata-ku, Kitakyushu 804-8550, Japan \\ *Corresponding author: nisikawa@mech.kyutech.ac.jp
}

( Manuscript received 16 June 2006; accepted 21 August 2006; published 31 August 2006 )

\begin{abstract}
The ultra thin film interferometry and conventional optical interferometry techniques are used to measure the central film thickness and friction force as a function of the dimensionless speed parameter. Experiments were conducted in point contacts with a mineral bright stock oil and a disk-like chemical compound by changing the temperature, entrainment velocity and surface roughness at a fixed slide-roll ratio. It has been found that the friction coefficient curve, i.e., the relationship between the friction coefficient and the dimensionless speed parameter, changes depending on lubrication regimes, even when the relationship between the central film thickness and the dimensionless speed parameter obeys EHL theory.
\end{abstract}

Keywords: point contact, surface roughness, film thickness, friction coefficient, lubrication regime, Stribeck friction curve

\section{Introduction}

Elastohydrodynamic lubrication (EHL) theory has brought about a large improvement in the working performance and durability of highly stressed non-conformal machine elements such as gears, rolling element bearings and traction drives. According to EHL theory ${ }^{1-3)}$, the film thickness and shape are mainly determined by the conditions at the entrance to the contact. Optical interferometry, ${ }^{4,5)}$ has experimentally proved the above theoretical result. The ultra thin film interferometry technique developed by Johnston et $\mathrm{al}^{6}$ ) has shown that the EHL film thickness equation is obeyed down to only a few nanometer ${ }^{7,8}$. This value is less than the roughness of conventional engineering surface.

The friction force between the contact surfaces is determined by the shear properties in the EHL conjunction. That is, when the surfaces are completely separated by lubricant, the friction or traction force is controlled by the lubricant rheology. It is well known that when the film factor, which is defined as the ratio of the minimum film thickness to the composite surface roughness, is less than 1 , the mixed lubrication regime is encountered and the friction force increases as the film factor decrease. In the mixed lubrication regime, the friction force is mainly determined by asperity interactions and boundary films ${ }^{9}$. That is, the Stribeck friction curve ${ }^{10)}$, which shows the relationship between the friction coefficient, $\phi$, and the dimensionless speed parameter, $U$, which is defined as $\eta u_{e} / E^{\prime} R$, can classify the regimes of lubrication.

The above mentioned facts suggest that the surface roughness plays important roles for the values of film thickness and friction force. However, if the relationship between the film thickness and the dimensionless speed parameter, $U$, obeys EHL theory, we may understand that two surfaces are completely separated by the EHL film. Hence, it seems that the relationship between the film thickness and the dimensionless speed parameter obtained by the ultra thin interferometry technique does not necessarily reflect the regimes of lubrication. Therefore, it seems to be very important to correlate the relationship between the film thickness and $U$ with the Stribeck friction curve.

The purpose of this paper is to make the Stribeck friction curve based on measurements of friction force using steel balls with different surface roughness, and to warn against the interpretation of the relationship between the film thickness and dimensionless speed parameter.

\section{Experimental procedure}

The ultra thin film interferometry technique ${ }^{6)}$ was mainly used to measure central film thickness. Rather thick film thickness was measured using conventional duochromatric optical interferometry ${ }^{5)}$. The measurement of thin film was carried out by reducing the entraining velocity.

The contact was formed between a $19.05 \mathrm{~mm}$ diameter 
steel ball and a glass disc. The reduced elastic modulus is $117 \mathrm{GPa}$. The balls having three kinds of arithmetic average surface roughness of $13 \mathrm{~nm}, 20 \mathrm{~nm}$ and $30 \mathrm{~nm}$ were used. The steel ball and glass disc can be separately driven. The friction force was also measured with the ultra thin film interferometry machine at a fixed slide-roll ratio as a function of entrainment velocity under a constant load.

The lubricants used were a mineral bright stock (BS) and a disk-like chemical compound (DL); their molecular

Table 1 Properties of lubricants used

\begin{tabular}{c|c|c|c|c}
\hline \multirow{2}{*}{ Lubricants } & \multicolumn{2}{|c|}{$\mathrm{BS}$} & \multicolumn{2}{c}{$\mathrm{DL}$} \\
\cline { 2 - 5 } & $20^{\circ} \mathrm{C}$ & $100^{\circ} \mathrm{C}$ & $20^{\circ} \mathrm{C}$ & $100^{\circ} \mathrm{C}$ \\
\hline $\begin{array}{c}\text { Atmospheric } \\
\text { Density, } \mathrm{kg} / \mathrm{m}^{3}\end{array}$ & 876 & 825 & 1032 & 981 \\
\hline $\begin{array}{c}\text { Atmospheric } \\
\text { Viscosity, Pa·s }\end{array}$ & 1.315 & 0.024 & 5.737 & 0.081 \\
\hline $\begin{array}{c}\text { Pressure-Viscosity } \\
\text { Coefficient, GPa }\end{array}$ & 24.0 & 9.7 & 17.9 & 7.8 \\
\hline
\end{tabular}

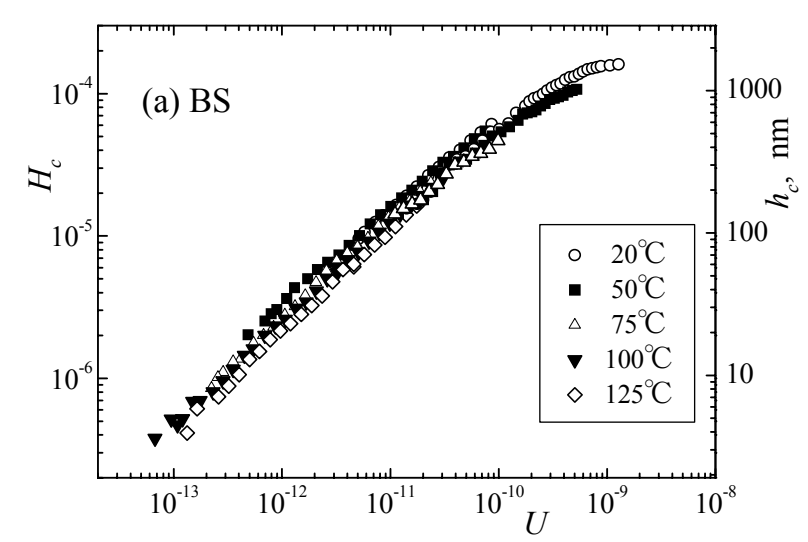

Fig.1 Central film thickness vs. dimensionless speed parameter $(\mathrm{Ra}=20 \mathrm{~nm})$
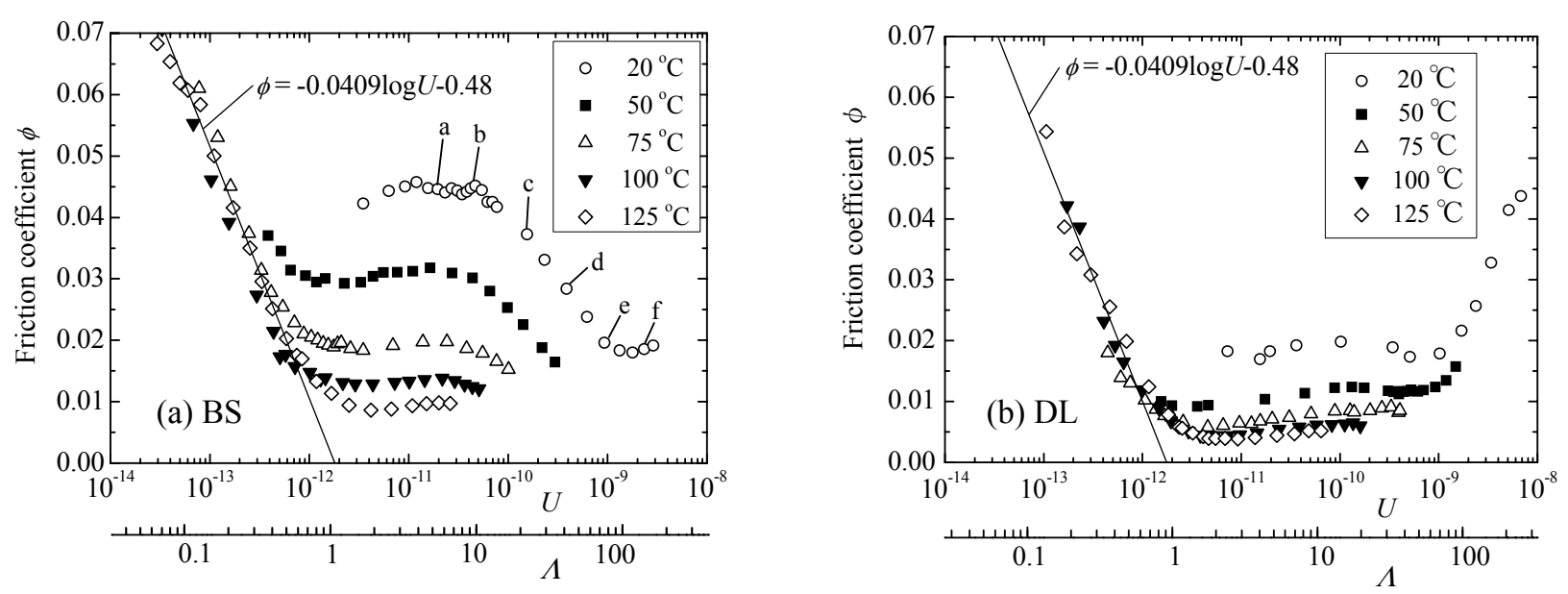

Fig.2 Stribeck friction curve $(\mathrm{Ra}=20 \mathrm{~nm})$ structures are quite different from each other. Table 1 shows their properties.

The experiments were carried out at temperatures of $20^{\circ} \mathrm{C}, 50^{\circ} \mathrm{C}, 75^{\circ} \mathrm{C}, 100^{\circ} \mathrm{C}$ and $125^{\circ} \mathrm{C}$ over a range of entrainment velocities of $0.003 \mathrm{~m} / \mathrm{s}$ to $3 \mathrm{~m} / \mathrm{s}$ at a slide-roll ratio of $\Sigma=-1$, which means that the ball speed is three times larger than the glass disc speed, and an applied load of $20 \mathrm{~N}$, which corresponds to a maximum Hertzian pressure of $0.53 \mathrm{GPa}$ and a dimensionless load parameter of $W=1.88 \times 10^{-6}$.

\section{Results and Discussion}

The central film thickness, $h_{c}$, obtained numerically by Chittenden et $\mathrm{al}^{11)}$ is given by $h_{c} \propto U^{0.67}$. Figure 1 is the experimental results showing the relationship between the dimensionless central film thickness, $H_{c}$, and $U$. Except for the range where $U$ is more than $2 \times 10^{-10}$, the gradients of all the plots nearly equal to 0.67 . That is, EHL theory seems to be applied down to $3 \mathrm{~nm}$; Smeeth et $\mathrm{al}^{8)}$ has described that EHL theory is obeyed down to $1 \mathrm{~nm}$ for a mineral oil.

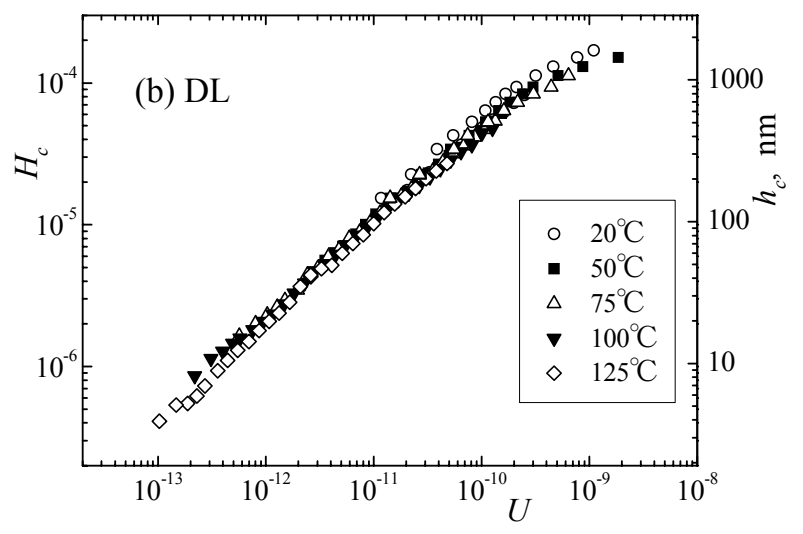




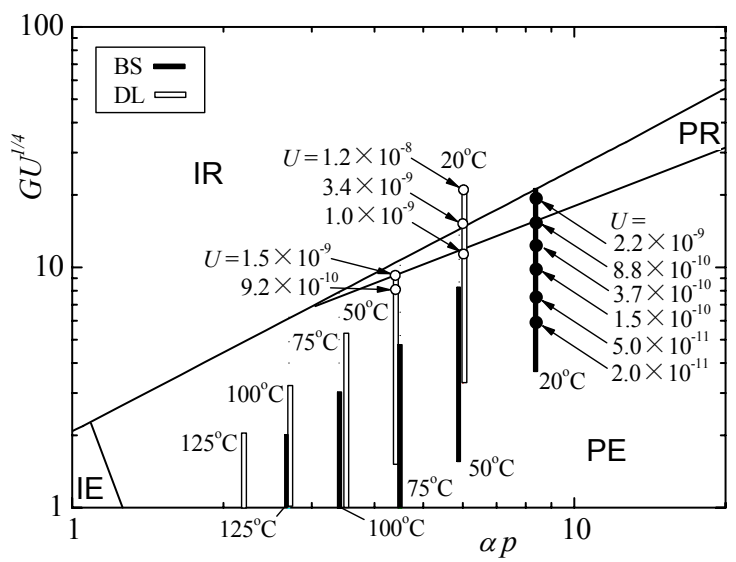

Fig.3 Lubrication regime map

Figure 2 shows the Stribeck friction curve, which corresponds to Fig. 1. It should be noted that although the friction coefficient depends complicatedly on $U$, there is not a wide difference in the tendency between both oils. In the region of $U<3 \times 10^{-12}$, the friction coefficient decreases with $U$. In the region of $3 \times 10^{-12}<U<1 \times 10^{-9}$, it increases and then decreases as $U$ increases. In $U>1 \times 10^{-9}$ at $20^{\circ} \mathrm{C}$, it increases with $U$.

Figure 3 is the map of lubrication regimes constructed by Ohno et $\mathrm{al}^{12)}$ by using the dimensionless parameters $G U^{1 / 4}$ and $\alpha p$ proposed by Greenwood ${ }^{13)}$. In Fig. 3, the experimental regions corresponding to Fig. 2 are shown by bars. It can be seen that experiments are mainly conducted in the piezoviscous-elastic (PE) regime. The values of $U$ for $\mathrm{BS}$ at $20^{\circ} \mathrm{C}$ shown in Fig. 3 correspond to alphabets shown in Fig. 2(a). The representative values of $U$ for DL at $20^{\circ} \mathrm{C}$ and $50^{\circ} \mathrm{C}$ are also indicated.

The plots suggest that the lubrication mode at $20^{\circ} \mathrm{C}$ for both lubricants shifts from the PE regime to the piezoviscous-rigid (PR) regime at around $U=1 \times 10^{-9}$, in particular, the mode for DL shifts from the PR regime to the isoviscous-rigid (IR) regime at around $U=3 \times 10^{-9}$. Figure 4 shows interferograms for BS oil corresponding to alphabets shown in Fig. 2(a). As $U$ increases, the region of a flat plateau bounded by a horseshoe shaped constriction decreases, resulting in the recovery of deformation of both surfaces. That is, the increase in the friction coefficient in the region where $U>1 \times 10^{-9}$ at $20^{\circ} \mathrm{C}$ shows that the lubrication for both lubricants is the PR regime or IR regime. This means that the friction coefficient also determines the boundary between the PE and PR regimes; its boundary line has been originally determined by film thickness equations ${ }^{2,12)}$.

Judging from Fig. 3, at least $20^{\circ} \mathrm{C}$ the region of $3 \times 10^{-12}<U<1 \times 10^{-9}$ is the EHL regime, i.e., $\mathrm{PE}$ regime, for both fluids. In the EHL regime, generally, the friction or traction coefficient increases linearly with increasing sliding velocity and is followed by a nonlinear shear thinning or bending off region and then a region where the friction coefficient falls. Since the results shown in Fig. 2 were obtained under a constant slide-roll ratio, the

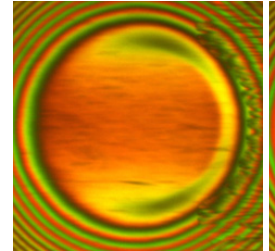

(a) $U=2.0 \times 10^{-11}$

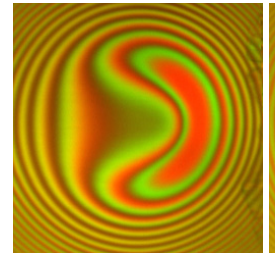

(d) $U=3.7 \times 10^{-11}$

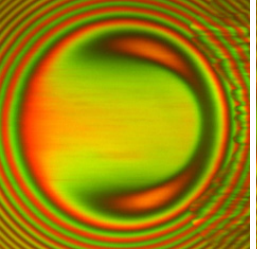

(b) $U=5.0 \times 10^{-11}$

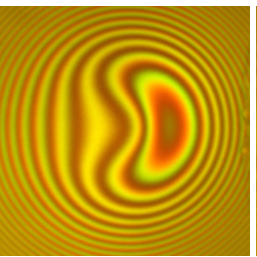

(e) $U=8.8 \times 10^{-11}$

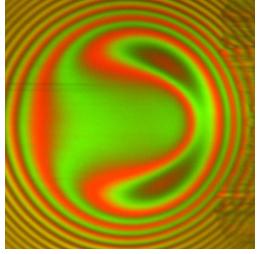

(c) $U=1.5 \times 10^{-10}$

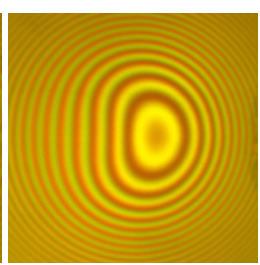

(f) $U=2.2 \times 10^{-10}$
Fig.4 Interferograms corresponding to alphabets shown in Fig. 2(a)

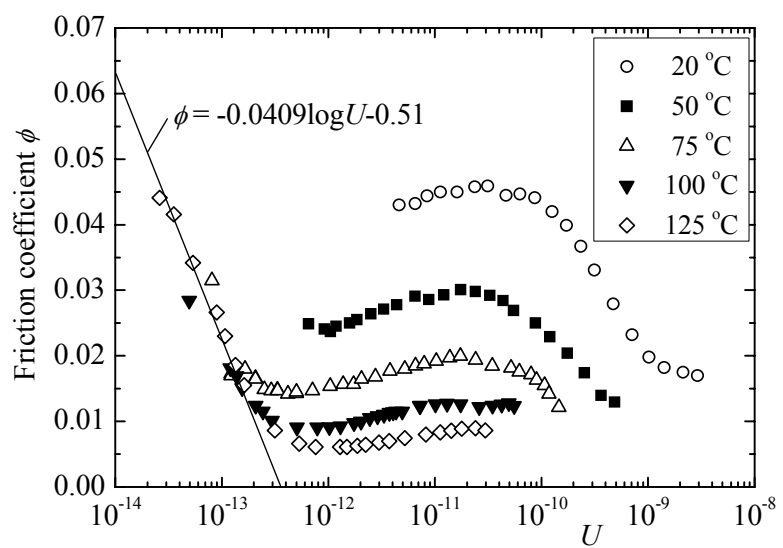

(a) $\mathrm{Ra}=13 \mathrm{~nm}$

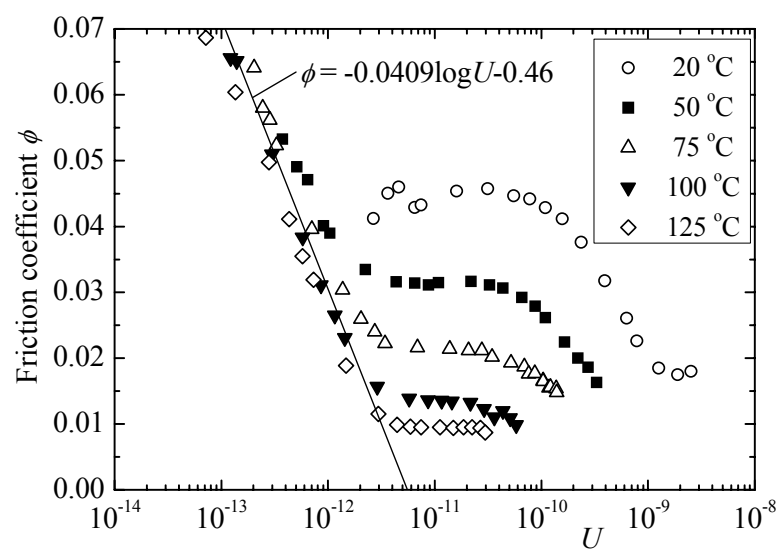

(b) $\mathrm{Ra}=30 \mathrm{~nm}$

Fig.5 Stribeck friction curve (BS)

increase of $U$ means the increase of the sliding velocity. The Stribeck friction curve corresponding to the region of $3 \times 10^{-12}<U<10^{-9}$ in Fig. 2 shows above characteristics in the traction curve.

Figure 5 shows the effect of surface roughness on the friction coefficient for BS oil. By comparing three 
Stribeck friction curves shown in Figs. 2 and 5, we can understand that the value of $U$ in the low $U$ region, where the friction coefficient begins to increases as $U$ decreases, increases as the surface roughness increases.

The film factor $\Lambda$ is defined as the ratio of the minimum film thickness to the arithmetic surface roughness of the steel ball. In this paper, the minimum film thickness was calculated from the measured central film thickness by using the film thickness equation induced by Chittenden et al ${ }^{11)}$. The average of $\Lambda$ values obtained at every temperature is shown as an abscissa in Fig. 2 for each fluid. It should be noticed that the friction coefficient begins to increase at roughly $\Lambda=1$ for both lubricants. Furthermore, as seen from the straight lines in Figs. 2 and 5, the friction coefficient increases with the same gradient with respect to $U$, regardless of lubricants used and the surface roughness. These facts suggest that the increase in the friction coefficient in the region of $\Lambda \leq 1$ is brought by an increase in frequency of direct contacts between both surfaces due to decreasing overall film thickness, i.e., the region is the mixed lubrication regime. It should be described that in film thickness measurements the glass disc was injured when the central film thickness was less than about $10 \mathrm{~nm}$.

\section{Conclusions}

Film thickness and friction coefficient were measured with fluids, those molecular structures are different from each other, and compared over a wide range of entrainment velocities. It has been found that even if the relationship between the central film thickness and dimensionless speed parameter obeys EHL theory, the actual lubrication regime is classified into three categories, i.e., mixed, EHL and hydrodynamic (piezoviscous-rigid or isoviscous-rigid) regions. This fact supports Wedeven's idea raised for a paper by Bair and Winer ${ }^{10)}$.

\section{Acknowledgments}

The authors wish to express their sincere thanks to Professor N. Ohno of Saga University for his helpful discussion and kind supply of the data of oils, which are provided by Idemitsu Kosan Co., Ltd. and Fuji Photo Film Co., Ltd.; and also Messrs. T. Nomiyama and K. Takada of Kyushu Institute of Technology for their cooperation. This work was supported by Grant-in-Aid for Scientific Research (No. 15002009) from the Ministry of Education, Culture, Sports, Science and Technology, Japan.

\section{References}

[1] Dowson, D. and Higginson, G. R., Elastohydrodynamic Lubrication, Pergamon Press, 1977.

[2] Hamrock, B. J. and Dowson, D., Ball Bearing Lubrication, John Wiley \& Sons, 1981.

[3] Gohar, R., Elastohydrodynamics, Imperial College Press, 2001.
[4] Gohar, R. and Cameron, A., "The Mapping of Elastohydrodynamic Contacts," ASLE Trans., 10, 1967, 215-225.

[5] Foord, C. A., Wedeven, L. D., Westlake, F. J. and Cameron, A., "Optical Elastohydrodynamics," Proc. Inst. Mech. Engrs., Part 1, 184, 28, 1969/70, 487-505.

[6] Johnston, G. J., Wayte, R. and Spikes, H. A., "The Measurement and Study of Very Thin Lubricant Films in Concentrated Contacts," Tribology Trans., 34, 2, 1991, 187-194.

[7] Guangteng, G. and Spikes, H. A., "Boundary Film Formation by Lubricant Base Fluids," Tribology Trans., 39, 2, 1996, 448-454.

[8] Smeeth, M., Spikes, H. A. and Gunsel, S., "Boundary Film Formation by Viscosity Index Improvers," Tribology Trans., 39, 3, 1996, 726-734.

[9] Glovnea, R. P., Olver, A. V. and Spikes, H. A., "Effectiveness of Boundary Lubricant Additives on Some Coated Surfaces," Proc. 31st Leeds-Lyon Symp. on Tribology, 2004, 135-143.

[10] Bair, S. and Winer, W. O., "Regions of Traction in Concentrated Contact Lubrication," ASME J. Lubric. Tech., 104, 1982, 382-391.

[11] Chittenden, R. J., Dowson, D., Dunn, J. F. and Taylor, C. M., "A Theoretical Analysis of Isothermal Elastohydrodynamic Lubrication of Concentrated Contacts I. Directing of Lubricant Entrainment Coincident with the Major Axis of the Hertzian Contact Ellipse," Proc. Roy. Soc. London, A, 397, 1985, 245-269.

[12] Ohno, N., Kuwano, N. and Hirano, F., "Diagrams for Estimation of the Solidified Film Thickness at High Pressure EHD Contacts," Proc. 20th Leeds-Lyon Symp. on Tribology, 1993, 507-518.

[13] Greenwood, J. A., "Film Thicknesses in Circular Elastohydrodynamic Contacts," Proc. Inst. Mech. Engrs., 202, C1, 1988, 11-17.

\section{Nomenclature}

$\begin{aligned} E^{\prime} & =\text { equivalent modulus }(\mathrm{Pa}) \\ G & =\text { dimensionless material parameter }\left(\alpha E^{\prime}\right) \\ H_{c} & =\text { dimensionless central film thickness }=h_{c} / R \\ h_{c} & =\text { central film thickness }(\mathrm{m}) \\ p & =\text { average pressure }(\mathrm{Pa}) \\ R & =\text { equivalent radius }(\mathrm{m}) \\ U & =\text { dimensionless speed parameter }=\eta u_{e} / E^{\prime} R \\ u_{s} & =\text { surface velocities of glass disc and steel ball }(\mathrm{m} / \mathrm{s}) \\ u_{e} & =\text { entrainment velocity }=\left(u_{g}+u_{s}\right) / 2(\mathrm{~m} / \mathrm{s}) \\ W & =\text { dimensionless load parameter }=w / E^{\prime} R^{2} \\ w & =\text { applied load }(\mathrm{N}) \\ \alpha & =\text { viscosity-pressure coefficient }\left(\mathrm{m}^{2} / \mathrm{N}\right) \\ \phi & =\text { friction coefficient } \\ \eta & =\text { ambient viscosity of lubricant }(\mathrm{Pa} \mathrm{s}) \\ \Lambda & =\text { film factor } \\ \rho & =\text { ambient density of lubricant }\left(\mathrm{kg} / \mathrm{m}^{3}\right) \\ \Sigma & =\text { Slide-roll ratio }=\left(u_{g}-u_{s}\right) / u_{e}\end{aligned}$

